\title{
Taxas de crescimento de mudas de Erythrina velutina em dois ambientes de crescimento
}

\author{
Mychelle Karla Teixeira de Oliveira ${ }^{*}$, Jeferson Luiz Dallabona Dombroski ${ }^{1}$, Artur Leônio Maia Fernandes ${ }^{1}$
}

\begin{abstract}
RESUMO: Erythrina velutina Willd., espécie arbórea reconhecida pela importância, não apenas para reflorestamento, como também ornamental, medicinal, artesanal, dentre outros usos. Neste contexto, este trabalho teve como objetivo avaliar as taxas de crescimento de mudas de Erythrina velutina em dois ambientes de crescimento. O experimento foi conduzido em delineamento inteiramente casualizado, com parcelas subdivididas no tempo. Foram utilizados dois níveis de luminosidade (pleno sol e 50\% de sombreamento). Ao longo do experimento foram realizadas coletas para avaliação de crescimento $(8,12,16,20$ e 24 semanas após transplantio). Sendo analisadas as seguintes variáveis: razão de área foliar (RAF), razão de peso foliar (RPF), área foliar específica (AFE), taxa de crescimento absoluto (TCA), taxa de crescimento relativo (TCR) e taxa assimilatória líquida (TAL). Os resultados obtidos demonstram que houve diferença significativa entre os ambientes estudados nas taxas de crescimento de mudas de Erythrina velutina. As taxas de crescimento de mudas de Erythrina velutina têm decréscimo quando na condição de pleno sol. É recomendado produzir mudas de Erythrina velutina na condição de $50 \%$ de sombreamento para obtenção de maiores taxas de crescimento.
\end{abstract}

Palavras-chave: mulungu, ecofisiologia, revegetação, sombreamento

\section{Growth rates of Erythrina velutina seedlings in two growth environments}

\begin{abstract}
Erythrina velutina Willd., tree species recognized for its importance, not only for reforestation, ornamental, medicinal, handicraft, but for several other uses. In this context, the aim of this work was to evaluate the growth rates of Erythrina velutina seedlings in two growth environments. Two shadow levels were used (full sunlight and $50 \%$ shade). The experiment was conducted in completely randomized blocks, with parts subdivided in time, with four repetitions, being the experimental unit represented by six seedlings. During the experiment samplings were realized to evaluate growth $(8,12,16,20$ and 24 weeks after transplanting). At each sampling date, the following characteristics were analyzed: leaf area ratio, leaf weight ratio, specific leaf area, absolute growth rate, relative growth rate and net assimilation rate. The results showed that there was a significant difference between the environments studied in the growth rates of Erythrina velutina seedlings. The growth rates of Erythrina velutina seedlings have decreased when in the full sun condition. It is recommended to produce Erythrina velutina seedlings in the condition of $50 \%$ shading to obtain higher growth rates.
\end{abstract}

Keywords: mulungu, ecophysiology, revegetation, shading

\section{INTRODUÇÃO}

Frente à carência de informações sobre o manejo e a análise de espécies florestais e os problemas ambientais que atingem os ecossistemas, reduzindo as áreas florestais, tornam-se importantes os trabalhos que colaborem com informações pertinentes para recuperação de áreas degradadas e recomposição da paisagem (TEIXEIRA et al., 2013). Assim, a implantação de povoamentos florestais destinados para a produção de madeira ou povoamentos mistos para fins de preservação ambiental e/ou restauração de áreas degradadas tem, em uma adequada formação de mudas, um dos fatores de maior importância (GONÇALVES et al., 2014).

Recebido em 09/08/2017; Aceito para publicação em 21/03/2018

${ }^{1}$ Universidade Federal Rural do Semi-Árido.

*E-mail: mymykar@gmail.com
Mulungu (Erythrina velutina Wild.) é uma espécie arbórea que pode ser encontrada em diferentes regiões do país, desde o Estado do Ceará até o de São Paulo, sendo comum em várzeas úmidas e margens de rios. É reconhecida a importância do mulungu, não apenas para reflorestamento, mas para diversas modalidades de uso. É empregada no paisagismo, e indicada para plantio em margens de corpos d'água, ruas, praças, avenidas, parques e jardins; utilizada na medicina popular devido a propriedades sudorífica, calmante, emoliente, anestésica, relaxante, contra insônia e anti-inflamatória; também tem uso na confecção de jangadas, brinquedos, tamancos, palitos de fósforo, mourões, estacas e caixotaria (LORENZI; MATOS, 
2008). O mulungu se destaca como tolerante à competição com outras espécies florestais pela disponibilidade por água, luz e nutrientes, pela rusticidade, resistência à seca e capacidade de fixar nitrogênio, características pertinentes de uma espécie própria para ser utilizada na recuperação de áreas degradadas (SANTOS et al., 2012).

Assim como se faz com várias espécies vegetais, por exemplo, Hymenaea parvifolia (DANTAS et al., 2009), e Moringa oleifera (OLIVEIRA et al., 2013). As análises de crescimento, como a taxa de crescimento absoluto e a taxa de crescimento relativo são feitas por alguns indicadores morfológicos e fisiológicos que inferem sob os processos vitais das plantas e, portanto, imprescindíveis como indicadores de qualidade (BENINCASA, 2003).

Vários estudos sobre resposta ao sombreamento de espécies arbóreas foram desenvolvidos, a exemplo de Hymenaea parvifolia (SILVA et al., 2007), Mimosa caesalpiniifolia (CÂMARA; ENDRES, 2008), Hymenaea courbaril e Enterolobium contortisiliqum (LIMA et al., 2010), Caesalpinia echinata (AGUIAR et al., 2011), Dipteryx alata (MOTA et al., 2012), Swietenia macrophylla (TEIXEIRA et al., 2013). No entanto, são inexistentes com a espécie mulungu.

Diante do exposto, e em virtude da importância de se conhecer o comportamento de espécies vegetais em relação à intensidade luminosa a que está submetida, principalmente na fase inicial de crescimento, conduziu-se esse experimento, avaliando-se as taxas de crescimento de mudas de Erythrina velutina em dois ambientes de produção.

\section{MATERIAL E MÉTODOS}

O experimento foi conduzido em casa de vegetação do Departamento de Ciências Vegetais da Universidade Federal Rural do Semi-Árido (UFERSA), localizado no município de Mossoró, RN. O município situa-se a $5^{\circ} 11^{\prime}$ de latitude sul e $37^{\circ} 20^{\prime}$ de longitude oeste e altitude de $18 \mathrm{~m}$. O clima local, segundo Thornthwaite, é classificado como DdAa', ou seja, semi-árido, megatérmico e com pequeno ou nenhum excesso d'água durante o ano. De acordo com Köppen é BSwh', o clima é seco e muito quente, tendo duas estações climáticas bem definidas, sendo uma seca, que geralmente compreende o período de junho a janeiro e uma chuvosa, entre os meses de fevereiro e maio (CARMO FILHO et al., 1991).

As sementes foram coletadas de árvores matrizes, no campus universitário da Universidade Federal Rural do Semi-Árido, e em seguida, realizou-se a superação da dormência pelo método de escarificação mecânica, com lixa $\mathrm{N}^{\circ} 8$, ao lado oposto ao hilo, e semeadas em bandejas plásticas perfuradas no fundo, com dimensões de $29 \times 22 \times 10$ $\mathrm{cm}$ de comprimento, largura e profundidade, respectivamente, utilizando areia lavada como substrato, na profundidade de $2 \mathrm{a} 3 \mathrm{~cm}$, colocando as sementes com o hilo para baixo.

Aos 28 dias após a semeadura conforme descrito logo acima, as plântulas foram transplantadas para sacos plásticos com capacidade para 2,5 litros, preenchidos com substrato composto por uma mistura de solo (Neossolo Quartzarênico) + esterco, na proporção 4:1. Antes do transplantio, retirou-se uma amostra do substrato para caracterização química, cujos resultados estão apresentados na Tabela 1.

Tabela 1. Características químicas do substrato utilizado.

\begin{tabular}{|c|c|c|c|c|c|c|c|c|c|c|c|c|c|}
\hline $\mathrm{pH}$ & $\mathrm{Na}^{+}$ & $\mathrm{Al}^{3+}$ & $\mathrm{K}^{+}$ & $\mathrm{Ca}^{2+}$ & $\mathrm{Mg}^{2+}$ & SB & $\mathrm{P}$ & $\mathrm{Cu}$ & $\mathrm{Zn}$ & $\mathrm{Fe}$ & $\mathrm{Mn}$ & C & MO \\
\hline & \multicolumn{6}{|c|}{----------- $\mathrm{cmol}_{\mathrm{c}} \mathrm{dm}^{-3}$} & \multicolumn{5}{|c|}{-------------'mg kg ${ }^{-1}$------------- } & $\mathrm{g} \mathrm{kg}^{-}$ & \\
\hline 7,60 & 2,29 & 0,00 & 1,49 & 3,30 & 2,00 & 9,08 & 235,07 & 0,40 & 7,40 & 76,00 & 22,40 & 3,32 & 5,73 \\
\hline
\end{tabular}

Análises realizadas no Laboratório de Análises de Solo, Água e Planta (LASAP) da UFERSA. SB - Soma de Bases.

Logo depois do transplantio das plântulas para os sacos plásticos, efetuou-se a distribuição das mesmas de acordo com os níveis de luminosidade a serem testados. As plantas foram irrigadas através de um sistema de irrigação utilizando microaspersores, realizando-se duas irrigações diárias (manhã e final da tarde).

$\mathrm{O}$ estudo foi disposto em delineamento inteiramente casualizado, com parcelas subdivididas no tempo, com quatro repetições, sendo a unidade experimental representada por seis plantas. Ao longo do experimento foram realizadas cinco coletas de plantas para avaliação de crescimento $(8,12,16,20$ e 24 semanas após transplantio).
Foram avaliados dois níveis de luminosidade, 50 e $100 \%$, sendo que no primeiro tratamento as plantas foram submetidas ao ambiente de sombrite com tela preta de $50 \%$ de sombreamento, ao passo que no segundo, disposto no lado externo do viveiro, ficaram expostas ao pleno sol.

A primeira coleta de dados foi realizada no dia 4 de novembro de 2010, e as demais em intervalos de 28 dias. Em cada coleta, as mudas foram analisadas quanto às seguintes características: razão de área foliar (RAF), razão de peso foliar (RPF), área foliar específica (AFE), taxa de crescimento absoluto (TCA), taxa de crescimento relativo (TCR) e taxa assimilatória líquida (TAL), de acordo com 
Benincasa (2003), calculadas pelas seguintes equações:

$$
\begin{aligned}
& \mathrm{RAF}=\frac{\mathrm{A} 2}{\mathrm{Pt} 2}\left(\mathrm{~cm}^{2} \mathrm{~g}^{-1}\right) \\
& \mathrm{RPF}=\frac{\mathrm{Pf}}{\mathrm{Pt} 2}\left(\mathrm{~g} \mathrm{~g}^{-1}\right) \\
& \mathrm{AFE}=\frac{\mathrm{A} 2}{\mathrm{Pt}}\left(\mathrm{cm}^{-2} \mathrm{~g}^{-1}\right) \\
& \mathrm{TCA}=\frac{(\mathrm{P} 2-\mathrm{P} 1)}{\Delta \mathrm{t}}\left(\mathrm{g} \mathrm{sem}^{-1}\right) \\
& \mathrm{TCR}=\frac{(\mathrm{ln} \mathrm{P} 2-\ln \mathrm{P} 1)\left(\mathrm{g} \mathrm{g}^{-1}\right. \text { semana }}{\Delta \mathrm{t})} \\
& \mathrm{TAL}=\frac{(\mathrm{P} 2-\mathrm{P} 1)}{(\mathrm{A} 2-\mathrm{A} 1)} \cdot \frac{(\ln \mathrm{A} 2-\ln \mathrm{A} 1)}{\Delta \mathrm{t}} \quad\left(\mathrm{g} \quad \mathrm{cm}^{-2}\right. \\
& \left.\mathrm{Emana}{ }^{-1}\right) \\
& \mathrm{Pt} 1=\text { Massa seca total da coleta anterior } \\
& \mathrm{Pt} 2=\text { Massa seca total da coleta atual } \\
& \mathrm{Pf}=\text { Massa seca de folha da coleta atual } \\
& \mathrm{A} 1=\text { Área foliar da coleta anterior } \\
& \mathrm{A} 2=\text { Área foliar da coleta atual } \\
& \text { ln }=\text { logaritmo neperiano } \\
& \Delta \mathrm{t}=\text { Intervalo de tempo entre as coletas }
\end{aligned}
$$$$
\text { semana } \left.^{-1}\right)
$$

A área foliar foi determinada utilizando o método do disco corrigido (FERNANDES, 2000). Para determinação da massa da matéria seca as mudas foram colocadas em estufa com circulação forçada de ar a temperatura de $65{ }^{\circ} \mathrm{C}$, até atingir massa constante, obtendo o acúmulo de massa seca através de pesagens sucessivas da matéria seca.

Os dados obtidos são homogêneos e normais, e foram submetidos à análise de variância pelo teste $\mathrm{F}$. As médias referentes aos ambientes foram comparadas pelo teste Tukey a 5\% de probabilidade, e análise de regressão para as épocas de avaliação. As análises estatísticas foram realizadas com o uso do programa estatístico SISVAR (FERREIRA, 2011).

\section{RESULTADOS E DISCUSSÃO}

\begin{tabular}{|c|c|c|c|c|c|c|}
\hline & $\begin{array}{l}\text { RAF } \\
\left(\mathrm{cm}^{2} \mathrm{~g}^{-1}\right)\end{array}$ & $\mathrm{AFE}$ & $\begin{array}{l}\text { RPF } \\
\left(\mathrm{g} \mathrm{g}^{-1}\right)\end{array}$ & $\begin{array}{l}\text { TCA } \\
\left(\mathrm{g} \mathrm{sem}^{-1}\right)\end{array}$ & $\begin{array}{l}\text { TCR } \\
\left(\text { g g sem }^{-1}\right)\end{array}$ & $\begin{array}{l}\text { TAL } \\
\left(\mathrm{g} \mathrm{cm}^{-2} \mathrm{sem}^{-1}\right)\end{array}$ \\
\hline Valores de F & $1635,11 * *$ & $363,72 * *$ & $4,80^{*}$ & $225,00 * *$ & $0,51^{\mathrm{ns}}$ & $351,22 * *$ \\
\hline $\mathrm{CV}(\%)$ & 9,12 & 19,21 & 15,12 & 15,11 & 10,30 & 21,20 \\
\hline Tratamentos & \multicolumn{6}{|c|}{ Valores médios } \\
\hline Sombreamento & $60,71 \mathrm{a}$ & $388,22 \mathrm{a}$ & $6,51 \mathrm{a}$ & $0,20 \mathrm{a}$ & $0,02 \mathrm{a}$ & $0,0003 \mathrm{~b}$ \\
\hline Pleno sol & $21,72 b$ & $139,20 \mathrm{~b}$ & $5,91 \mathrm{~b}$ & $0,12 \mathrm{~b}$ & $0,02 \mathrm{a}$ & $0,0010 \mathrm{a}$ \\
\hline
\end{tabular}

Houve diferença significativa ao nível de $1 \%$ de probabilidade entre os tratamentos para RAF, AFE, TCA e TAL, enquanto RPF, ao nível de $5 \%$ de probabilidade, e para TCR, não houve efeito significativo. Para RAF, AFE e TCA, os maiores valores foram obtidos nas mudas produzidas em condição de sombreamento, sendo aproximadamente 180,179 e $83 \%$ superiores àquelas mantidas a sol pleno. No entanto, para TAL, ocorreu redução de $68 \%$ na condição de sombreamento (Tabela 2).

Tabela 2. Resumo da análise de variância, valores de $\mathrm{F}$ e valores médios para as variáveis: razão de área foliar (RAF), área foliar específica (AFE), razão de peso foliar (RPF), taxa de crescimento absoluto (TCA), taxa de crescimento relativo (TCR), e taxa assimilatória líquida (TAL) de Erythrina velutina, nos dois ambientes de crescimento.

Médias seguidas pela mesma letra nas colunas não diferem entre si pelo teste de Tukey $(\mathrm{p} \leq 0,05)$.

*, ** significativo a $5 \%$ e $1 \%$ de probabilidade, respectivamente, pelo teste $\mathrm{F}$. ns não-significativo pelo teste $\mathrm{F}$.

Sem - semanas

Para RAF, houve diferença significativa, sendo os valores superiores em 40,65, 253, 382 e 577\%, na condição de sombreamento, em comparação à condição de pleno sol, às $8,12,16,20$ e 24 semanas após transplantio, respectivamente (Figura 1A). Para ambos os tratamentos houve comportamento linear ao longo do tempo, para RAF, resultando em 73,51 $\mathrm{cm}^{2} \mathrm{~g}^{-1}$ na condição de sombreamento, e $8,39 \mathrm{~cm}^{2} \mathrm{~g}^{-1}$ na condição de pleno sol, 24 semanas após transplantio (Figura 1). 


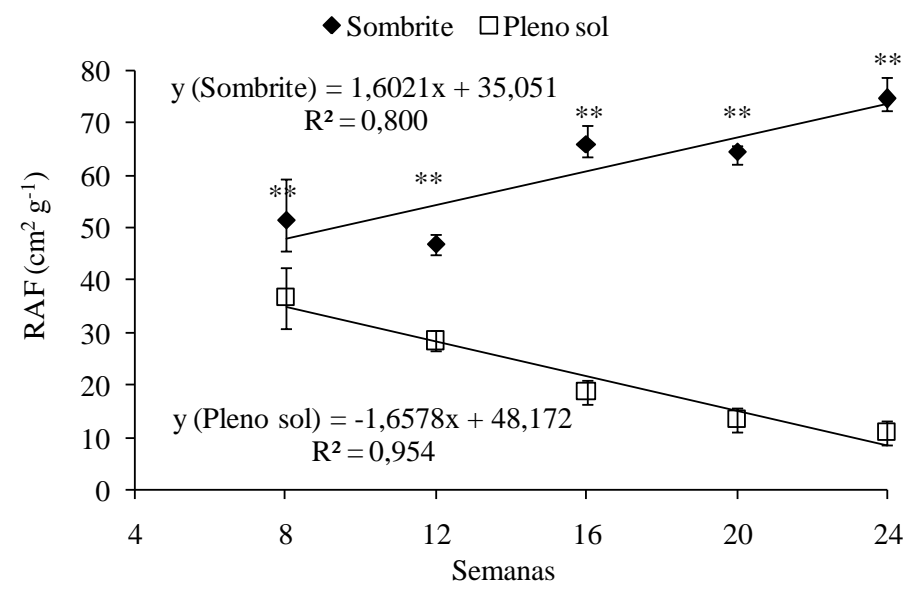

Figura 1. Razão de área foliar (RAF) de Erythrina velutina em dois ambientes de crescimento.

No entanto, para RPF não foi observada diferença significativa, às 8,12 e 20 semanas após transplantio, sendo os valores médios 6,6, 7,6 e 6,0, respectivamente. Por outro lado, na condição de sombreamento, às 16 e 24 semanas após transplantio, a RPF foi superior em $34 \%$ e $20 \%$, respectivamente (Figura 2). Houve comportamento polinomial para RPF, em ambos os tratamentos, sendo observados valores de sete, na condição de sombreamento, ao passo que na condição de pleno sol foi observado valor quatro, na $24^{\mathrm{a}}$ semana após o transplantio (Figura 2).

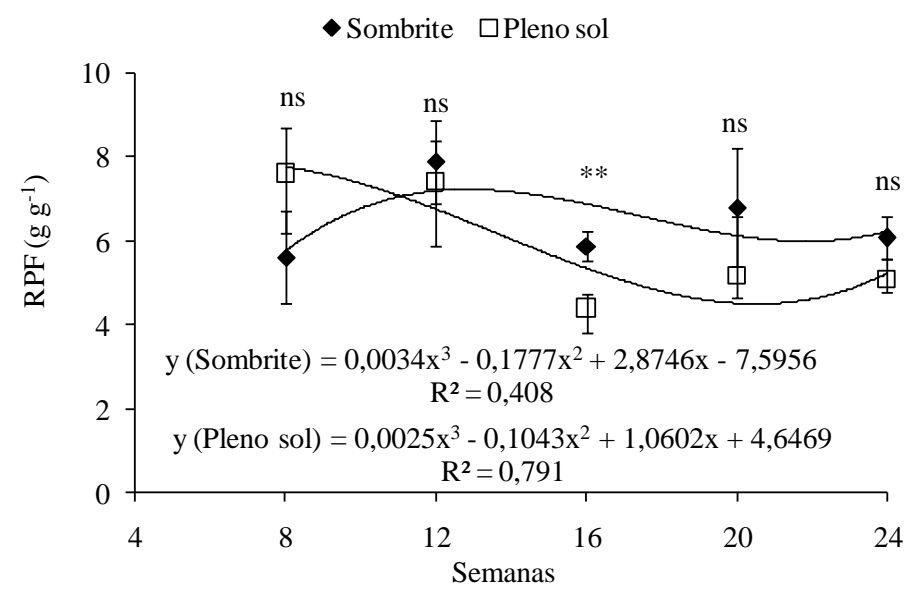

Figura 2. Razão de peso foliar (RPF) de Erythrina velutina em dois ambientes de crescimento.

Os resultados demonstram que a área foliar útil para a fotossíntese das mudas de mulungu, em condição de $50 \%$ de sombreamento, foi maior em todas as avaliações. A RAF expressa a área foliar útil para a fotossíntese, representando a relação entre a área foliar responsável pela interceptação da energia luminosa e $\mathrm{CO}_{2}$ e a massa seca total, resultado da fotossíntese, sendo esse um componente morfofisiológico (BENINCASA, 2003). Em trabalho avaliando mudas de Caesalpinia pyramidalis, os autores observaram que à medida que o nível de sombreamento aumentou, a RAF diminuiu (DANTAS et al., 2009). Em mudas de Bombacopsis glabra, foram observados maiores valores quando cultivadas sob $50 \%$ de sombreamento (SCALON et al., 2003).

Considerando que as folhas são órgãos fonte, responsáveis pela produção de assimilados a partir da fotossíntese e que os drenos dependem da exportação dos açúcares produzidos nas folhas (BENINCASA, 2003), a RPF das mudas de mulungu expressa fração de matéria seca retida nas folhas e não exportada para os demais órgãos. Podese inferir, portanto, que as folhas que se desenvolveram na condição de pleno sol, exportaram menos fotoassimilados que aquelas que foram mantidas na condição de sombreamento.

Não foi observada diferença significativa, para AFE na $8^{\text {a }}$ semana após transplantio, sendo o valor médio $285,10 \mathrm{~cm}^{2} \mathrm{~g}^{-1}$. Por outro lado, após 12,16 , 20 e 24 semanas depois do transplantio, na condição de sombreamento, os valores foram superiores em 76, 369, 528 e 712\%, respectivamente (Figura 3). Foi observado comportamento quadrático em ambos os tratamentos, resultando em $451,15 \mathrm{~cm}^{2} \mathrm{~g}^{-1}$ na condição de sombreamento, ao passo que na 
condição de pleno sol $53,28 \mathrm{~cm}^{2} \mathrm{~g}^{-1}$, as 24 semanas após transplantio (Figura 3). Sob sombreamento, as plantas aumentam sua superfície foliar, proporcionando a maior interceptação de luz solar, essencial para a atividade fotossintética, resultando em aumento no crescimento (TEIXEIRA et al., 2013).

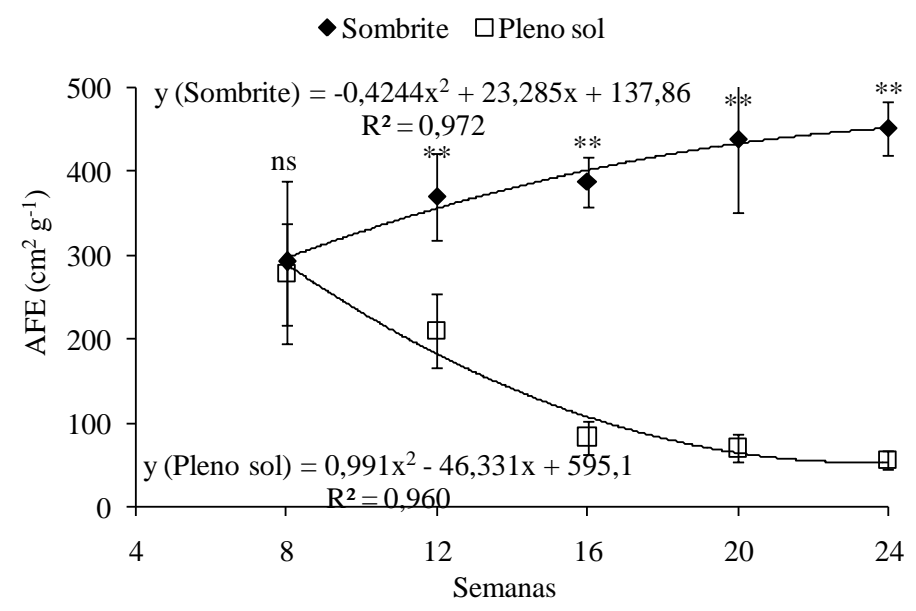

Figura 3. Área foliar específica (AFE) de Erythrina velutina em dois ambientes de crescimento.

A AFE é expressa pela razão entre a área foliar e a massa seca das folhas. A área foliar é um componente morfofisiológico, e a massa, componente anatômico de uma espécie vegetal, pois está relacionado à composição interna (número e tamanho) das células do mesófilo (BENINCASA, 2003).

Foi observada diferença significativa para TCA, com comportamento linear em ambos os tratamentos, resultando em de $0,31 \mathrm{~g} \mathrm{semanas}^{-1}$ na condição de sombreamento, e 0,18 $\mathrm{g} \mathrm{semanas}^{-1}$ na condição de pleno sol, na $24^{\mathrm{a}}$ semana após o transplantio (Figura 4). As mudas mantidas em condição de sombreamento apresentaram valores superiores em 239; 38; 114 e 60\%, em comparação à condição de pleno sol, na $12^{\mathrm{a}}, 16^{\mathrm{a}}, 20^{\mathrm{a}}$ e $24^{\mathrm{a}}$ semana após transplantio, respectivamente (Figura 4).

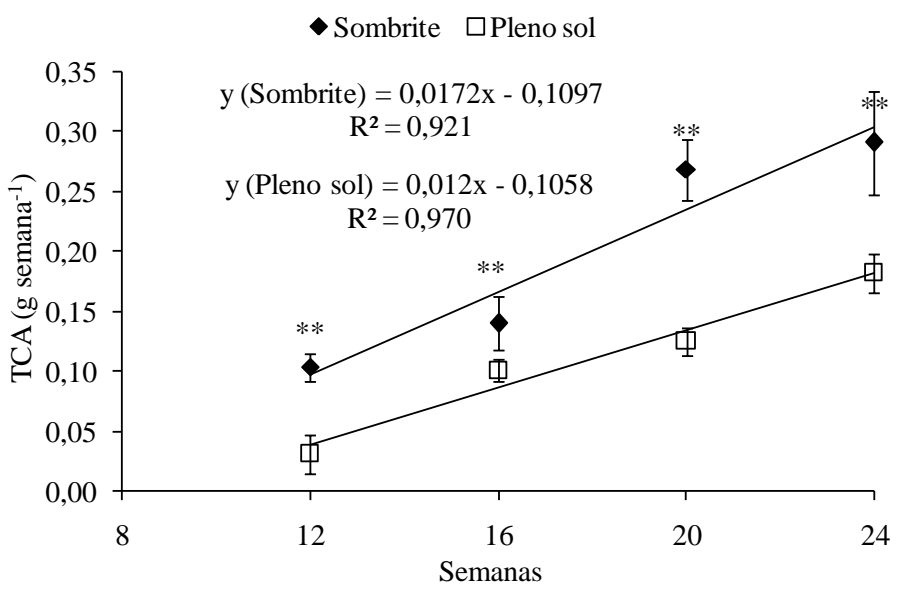

Figura 4. Taxa de crescimento absoluto (TCA) de Erythrina velutina em dois ambientes de crescimento.

Em condição de diferentes intensidades luminosas $(0 \%, 30 \%, \quad 50 \%$ e $75 \%$ de sombreamento), Dantas et al. (2009) não verificaram diferença significativa entre os tratamentos, nos parâmetros TCA e AFE, em mudas de Caesalpinia pyramidalis.

Não foi observada diferença significativa para TCR, sendo os valores médios 0,017 e $0,015 \mathrm{~g} \mathrm{~g}^{-1}$ semana $^{-1}$, nas $12^{\mathrm{a}}$ e $24^{\mathrm{a}}$ semana após o transplantio, respectivamente. Houve comportamento polinomial para TCR, em ambos os tratamentos, sendo observados valores $0,015 \mathrm{~g} \mathrm{~g}^{-1}$ semana $^{-1}$ na condição de sombreamento, e $0,012 \mathrm{~g} \mathrm{~g}^{-1}$ semana $^{-1}$ na condição de pleno sol, na $24^{\mathrm{a}}$ semana após transplantio (Figura 5). 


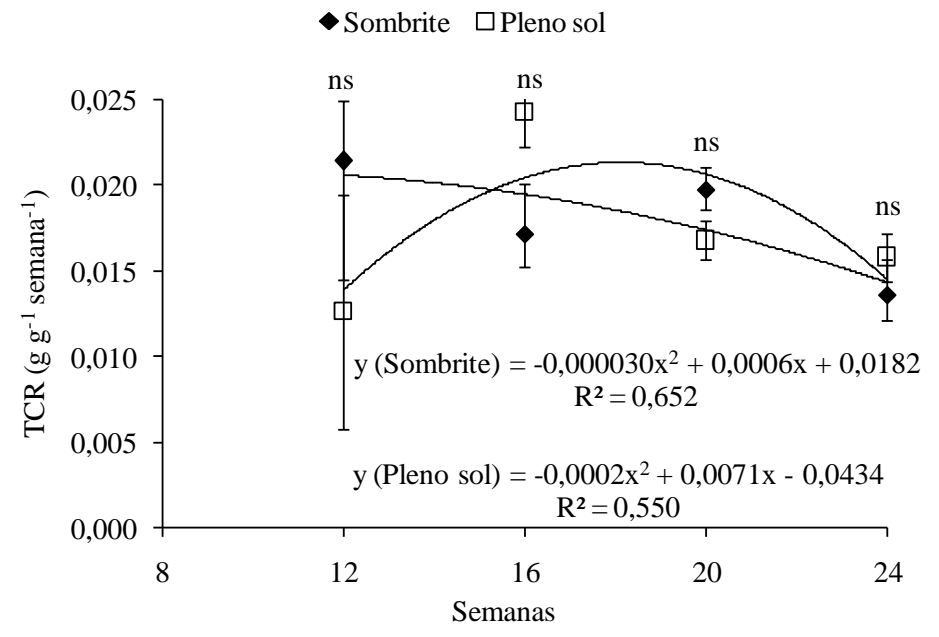

Figura 5. Taxa de crescimento relativo (TCR) de Erythrina velutina em dois ambientes de crescimento.

A TCR é a medida da rapidez com que uma planta cresce quando comparada com o seu tamanho inicial (BENINCASA, 2003). A capacidade de crescer rapidamente é um importante mecanismo de adaptação das espécies quando sombreadas, o que constitui uma estratégia para escapar às condições de baixa intensidade luminosa. Em mudas de Caesalpinia pyramidalis sob diferentes intensidades luminosas, os autores verificaram que, em condição de 30\% de sombreamento, apresentaram maior TCR (DANTAS et al., 2009). No entanto, para mudas de Colubrina glandulosa, o nível de $50 \%$ de sombreamento provocou maior TCR (CAUS;
PAULILO, 2000). Vários outros trabalhos indicam que a condição de $50 \%$ de luminosidade pode ser recomendada para a formação de mudas (SIEBENEICHLER et al., 2008). Isto indica existência de plasticidade, o que reflete no aumento potencial da captura de luz, importante para manter o crescimento e a sobrevivência das mudas em baixa luminosidade.

Em relação à TAL, foi verificada diferença significativa entre os tratamentos a partir da $16^{\mathrm{a}}$ semana após transplantio, com comportamento polinomial, em ambos os tratamentos, com valores inferiores na condição de sombreamento (Figura 6).

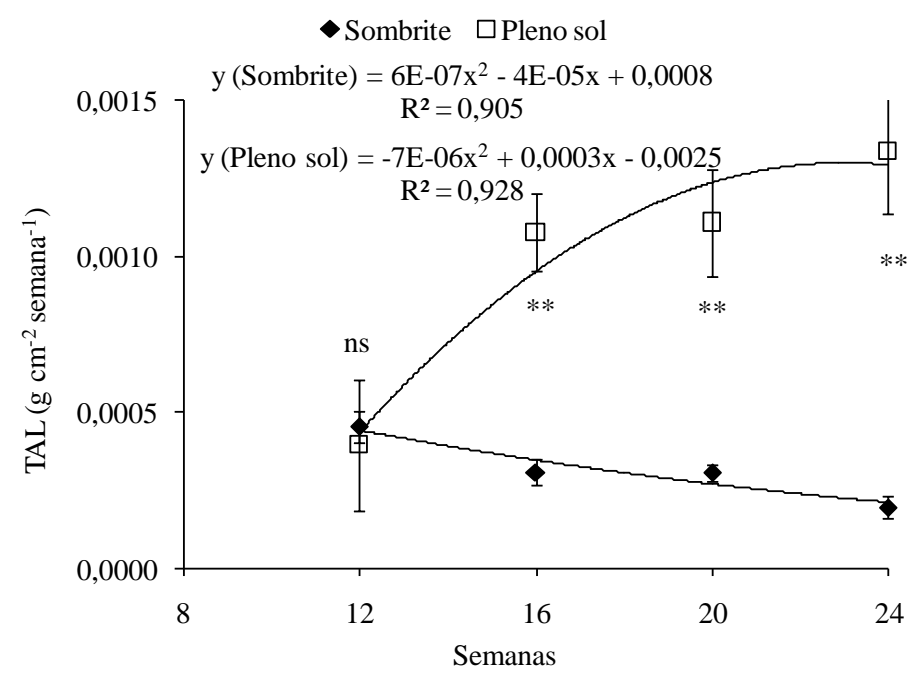

Figura 6. Taxa assimilatória líquida (TAL) de Erythrina velutina em dois ambientes de crescimento.

A TAL expressa a taxa de fotossíntese líquida, em termos de matéria seca produzida por unidade de área foliar. Desta forma, a TAL indica a eficiência das folhas para produção de biomassa (BENINCASA, 2003). Então, de acordo com os resultados obtidos, infere-se maior eficiência das folhas na condição de luminosidade para produção de biomassa.

\section{CONCLUSÕES}

1. As taxas de crescimento de mudas de Erythrina velutina têm decréscimo quando na condição de pleno sol.

2. É recomendado produzir mudas de Erythrina velutina na condição de 50\% de sombreamento para obtenção de maiores taxas de crescimento. 


\section{AGRADECIMENTOS}

Os autores agradecem ao Conselho Nacional de Desenvolvimento Científico e Tecnológico (CNPq), pela concessão de bolsa da primeira autora, à Universidade Federal Rural do Semi-Árido (UFERSA) e ao Programa de Pós-Graduação em Fitotecnia (PPGFITO), por permitir o ingresso na instituição e no programa de pós-graduação.

\section{REFERÊNCIAS}

AGUIAR, F. F. A.; KANASHIRO, S.; TAVARES, A. R.; NASCIMENTO, T. D. R; ROCCO, F. M. Crescimento de mudas de pau-brasil (Caesalpinia echinata Lam.) submetidas a cinco níveis de sombreamento. Revista Ceres, Viçosa, v. 58, n. 6, p.729-734, 2011.

BENINCASA, M. M. P. Análise de crescimento de plantas: noções básicas. Jaboticabal: FUNEP, 2003. 41p.

CÂMARA, C. A.; ENDRES, L. Desenvolvimento de mudas de duas espécies arbóreas: Mimosa caesalpiniifolia Benth. e Sterculia foetida sob diferentes níveis de sombreamento em viveiro. Floresta, Curitiba, v. 38, n. 1, p. 43-51, 2008.

DANTAS, B. F.; LOPES, A. P.; SILVA, F. F. S.; LÚCIO, A. A.; BATISTA, P. F.; PIRES, M. M. M. L.; ARAGÃO, C. A. Taxas de crescimento de mudas de catingueira submetidas a diferentes substratos e sombreamentos. Revista Árvore, Viçosa, v. 33, n. 3, p. 413-423, 2009.

DUTRA, T. R.; GRAZZIOTTI, P. H.; SANTANA, R. C.; MASSAD, M. D. Desenvolvimento inicial de mudas de copaíba sob diferentes níveis de sombreamento e substratos. Revista Ciência Agronômica, Fortaleza, v. 43, n. 2, p. 321-329, 2012.

FERNANDES, P. D. Análise de crescimento e desenvolvimento vegetal. Campina Grande: UFPB, Departamento de Engenharia Agrícola, 2000.

FERREIRA, D. F. Sisvar: A computer statistical analysis system. Ciência e Agrotecnologia, Lavras, v. 35, n. 6, p. 1039-1042, 2011.

GONÇALVES, E. O.; PETRI, G. M; CALDEIRA, M. V. W; DALMASO, T. T.; SILVA, A. G. Crescimento de mudas de Ateleia glazioviana em substratos contendo diferentes materiais orgânicos. Floresta e Ambiente, Rio de Janeiro, v. 21, n. 3, p. 339-348, 2014.

CARMO FILHO, F.; ESPÍNOLA SOBRINHO, J.; MAIA NETO, J. M. Dados climatológicos de Mossoró: Um município semi-árido nordestino. Mossoró, Escola Superior de Agricultura de Mossoró, 1991. 121p.

CAUS, C.; PAULILO, M. T. S. Influência da quantidade de luz no crescimento inicial de duas espécies arbóreas da mata atlântica. Insula, Florianópolis, v. 29, n. 36, p. 107115. 2000.
LIMA, A. L. S.; ZANELlA, F.; CASTRO, L. D. M. Crescimento de Hymenaea courbaril L. var. Stilbocarpa (Hayne) Lee et Lang. e Enterolobium contortisiliquum (Vell.) Morong (Leguminosae) sob diferentes níveis de sombreamento. Acta Amazônica, Manaus, v. 40, n. 1, p. 43-48, 2010.

LIMA, J. D.; SILVA, B. M. S.; MORAES, W. S.; DANTAS, V. A. V.; ALMEIDA, C. C. Efeitos da luminosidade no crescimento de mudas de Caesalpinia ferrea Mart. ex Tul. (Leguminosae, Caesalpinoideae). Acta Amazônica, Manaus, v. 38, n. 1, p. 5-10, 2008.

LORENZI, H.; MATOS, F. J. A. Plantas medicinais no Brasil: Nativas e exóticas cultivadas. 2.ed. Nova Odessa: Instituto Plantarum de Estudos da Flora Ltda; 2008.

MOTA, L. H. S.; SCALON, S. P. Q.; HEINZ, R. Sombreamento na emergência de plântulas e no crescimento inicial de Dipteryx alata (Vog.). Ciência Florestal, Santa Maria, v. 22, n. 3, p. 423-431, 2012.

OLIVEIRA, F. A.; OLIVEIRA, M. K. T.; SILVA, R. C. P.; SILVA, O. M. P.; MAIA, P. M. E.; CÂNDIDO, W.S. Crescimento de mudas de moringa em função da salinidade da água e da posição das sementes nos frutos. Revista Árvore, Viçosa, v. 37, n. 1, p. 79-87, 2013.

SANTOS, P. L.; FERREIRA, R. A.; ARAGÃO, A. G.; AMARAL, L. A.; OLIVEIRA, A. S. Estabelecimento de espécies florestais nativas por meio de semeadura direta para recuperação de áreas degradadas. Revista Árvore, Viçosa, v. 36, n. 2, p. 237-245, 2012.

SCALON, S. P.Q.; MUSSURY, R. M.; RIGONI, M. R.; SCALON FILHO, H. Crescimento inicial de mudas de Bombacopsis glabra (Pasq.) A. Robyns sob condição de sombreamento. Revista Árvore, Viçosa, v. 27, n. 6, p. 753-758, 2003.

SIEBENEICHLER, S. C.; FREITAS, G. A.; SILVA, R. R.; ADORIAN, G. C.; CAPELLARI, D. Características morfofisiológicas em plantas de Tabebuia heptaphyilla (vell.) tol. em condições de luminosidade. Acta Amazônica, Manaus, v. 38, n. 3, p. 467- 472, 2008.

SILVA, B. M. S.; LIMA, J. D.; DANTAS, V. A. V.; MORAES, W. S.; SABONARO, D. Z. Efeito da luz no crescimento de mudas de Hymenaea parvifolia Huber. Revista Árvore, Viçosa, v. 31, n. 6, p. 1019-1026, 2007.

TEIXEIRA, W. F.; FAGAN, E. B.; SILVA, J. O.; SILVA, P. G.; SILVA, F. H.; SOUSA, M. C.; CANEDO, S. C. Atividade da enzima nitrato redutase e crescimento de Swietenia macrophylla King sob efeito de sombreamento. Floresta e Ambiente, Rio de Janeiro, v. 20, n. 1, p. 91-98, 2013. 